\title{
Die vererbte Tradition - Habsburger Testamente als Instrumente und Spiegel konfessioneller und politischer Kontinuitäten
}

\section{Einleitende Betrachtung - frühneuzeitliche Herrscher- testamente im Alten Reich}

Herrschaftswissen von Fürsten basierte auf der eigenen Regierungserfahrung sowie - im 16. Jahrhundert allmählich beginnend und bis zum 18. Jahrhundert ausgereift - auf der Auseinandersetzung mit Akten und Gutachten von Beamten, auf Gesprächen mit Räten und Experten, auf Audienzen sowie eigenen oder von Inspektoren ausgeführten Reisen durch das Land. Eine Nutzung des erworbenen Wissens ausschließlich für die Dauer der eigenen Regierung hätte zur Folge gehabt, dass die nächste Herrschergeneration davon ausgeschlossen geblieben wäre, dieses Wissen hätte neu erwerben müssen oder dass es vielleicht sogar verloren gegangen wäre. Es ist deshalb kein Zufall, dass gerade im 16. Jahrhundert im Rahmen der allgemeinen Tendenz zur Systematisierung von Wissen auch die Fürsten nach einem Weg suchten, ihre Wissensbestände $\mathrm{zu}$ fixieren, langfristig zu erhalten und zum Nutzen späterer Generationen zu vererben. Aus dem Herrschaftswissen ergaben sich für einen Fürsten langfristige Zielsetzungen und das Bestreben, vorausschauend die Existenz der Dynastie zu sichern und ihren weiteren Aufstieg in der Zukunft auch über den eigenen Tod hinaus zu koordinieren. Der Bestand des Herrschaftswissens sollte also gesichert werden und für die nachfolgenden Herrschergenerationen handlungsanleitend wirken.

Den Monarchen ging es um den Transfer von herrschaftlichem, dynastischem und konfessionellem Sach-, Methoden- und Orientierungswissen mit der Intention, Brüche und Krisen in Folge ihres Todes zu vermeiden und eine politische, dynastische und konfessionelle Kontinuität über mehrere Generationen hinweg zu erlangen. Bestimmte Teile des Herrschaftswissens wurden deshalb zu einem Wissenskanon zusammengefasst, der weitgehend unverändert tradiert und damit auch formalisiert überliefert werden sollte. Hierzu zählte beispielsweise die Konfession, aus der sich nicht nur die Frage der Lebensführung des einzelnen Fürsten ergab, sondern aus deren politischem Kontext das Regelwerk für die Leitung des Gemeinwesens und damit eine entsprechende Herrschaftsauffassung erwuchs. Zudem betraf dies auch die Aufstiegs- und Machterhaltungsmechanismen der Dynastien wie die Erbfolge oder die Auswahl möglicher vormundschaftlicher Regenten oder Regentinnen. In der Tradierung und formalisierten Überlieferung dieses Wissenskanons lag für die Fürsten eine der Strategien für ihren langfristigen Statuserhalt und die Konfliktvermeidung beim Herrscherwechsel. Dies bedingte jedoch die Einsicht des Nachfolgers, als neuer Träger des Herrschaftswissens, die bestehende Tradition weiterzuführen. Die Einsicht des Erben sollte auch durch eine das Gewissen bindende Recht- 
lichkeit erreicht werden. Damit war ein geeignetes Medium mit rechtlichen Bindungsmöglichkeiten für den Transfer von Herrschaftswissen notwendig. Der Wahl von Rechtsdokumenten wie Testamenten kam deshalb für den Erhalt dieses Wissens über große Zeiträume hinweg ein hoher operativer und zukunftssichernder Wert zu. ${ }^{1}$ Es ging den Fürsten um die Eindeutigkeit des Wissenstransfers und um die Verbindlichkeit der Informationen an den Nachfolger sowie um die Standardisierung und Kodifizierung der Informationsträger. Die Testamente vieler Dynastien belegen, wenn sie im Längsschnitt betrachtet werden, wie Chroniken den mehr oder weniger raschen Aufstieg und die Erfolge der Dynastie sowie die gewählten Strategien. Die Aufbewahrung dieses urkundengebundenen Informationssystems zum dynastischen Herrschaftswissen erfolgte seit dem 16. Jahrhundert immer professioneller in Registraturen und Archiven, also kontrollierten und sicheren Räumen. Die Verfügbarkeit der Informationen für die nächste Generation war die grundlegende Voraussetzung für die Weitergabe des Wissens und förderte in besonderem Maße die Traditionsbildung. Der begrenzte Zugang zu den Archiven durch den Herrscher und wenige vertraute Beamte verlieh den Testamenten, ebenso wie die Vermittlung ihrer Inhalte lediglich an eine begrenzte, ausgewählte Öffentlichkeit anlässlich der Testamentseröffnung, den Charakter eines Geheimdokuments, allerdings einem mit einem breiteren Gültigkeitsformat.

Die Testierpraxis von Fürsten des Alten Reiches war dadurch gekennzeichnet, dass sie sich seit dem 16. Jahrhundert zum Erlass letztwilliger Verfügungen verstärkt des Testaments in Form einer Urkunde nach Römischem Recht bedienten. Die darin verankerten Regelungen sollten daneben aber auch nach fürstlichem Privatrecht

\footnotetext{
${ }^{1}$ Vgl. grundlegend RICHTER, Fürstentestamente. Ich danke meiner studentischen Hilfskraft Christian Scholl für Literaturrecherchen und Korrekturen.
}

Gültigkeit besitzen, nicht zuletzt deshalb, weil die römisch-rechtliche Bestimmung, Söhnen und Töchtern gleiches Erbe oder einen Pflichtteil zu geben, inhaltlich den in einigen Dynastien bereits geschlossenen Hausverträgen mit Primogeniturregelung oder agnatischer Erbfolge sowie bestehenden Verträgen zur Erbverbrüderung entgegen stand. ${ }^{2}$

Die Habsburger beanspruchten deshalb wie andere Reichsfürsten auch das Hoheitsrecht, in Privatsachen ohne Einhaltung der Formalitäten des Römischen Rechts, sondern nach den dazugehörigen Ausnahmeregelungen testamenti principi oblati $\mathrm{zu}$ bestimmen. ${ }^{3}$

Im Wesentlichen verfügten die Testamente der Habsburger über einen anderen Fürstentestamenten vergleichbaren Aufbau, der grundsätzlich dem Urkundenschema folgte, aus dem römisch-rechtlichen Testament die Erbeinsetzung (heredis institutio) übernahm, über eine Kodizillarklausel und Zeugen verfügte, notariell beurkundet wurde, jedoch im Gegensatz zu den meisten Bürgertestamenten durch appellative und informative Passagen ergänzt wurde. ${ }^{4}$

Die Errichtung der Testamente unter Zuhilfenahme einiger besonders vertrauter, in der Regel juristisch ausgebildeter Räte verlief - ähnlich wie bei den anderen reichsfürstlichen Häusern im Wesentlichen gleich. Dabei ist zu beobachten, dass die Habsburger ihre Testamente ebenfalls als „Verordnung" oder "befelch" verstanden, wie Kaiser Ferdinand II. in seinem Testament aus dem Jahr 1621 schreibt. Ihm ging es darum,

\footnotetext{
2 PÜTTER, Teutsches Staats- und Fürstenrecht 1, Cap. V 189-192.

${ }^{3}$ Dazu Myler ab Ehrenbach: „[...] principes et status imperii in suis territoriis imperatori potius quam praefectis praetorio aequiparari, ac imperatoris iure censeri." MYLER $\mathrm{AB}$ EHRENBACH, Archologia ordinum imperialium Cap. 23, § 2, 222. Zur Verschränkung von Hoheitsrechten und Eigentum in mittelalterlichen Testamenten vgl. KLIPPEL, Herrschaft, Testament und Familie 25-27.

${ }^{4}$ RICHTER, Fürstentestamente 39-44.
} 
dass seinem letzten Willen ,[...] durch Unsere Erben und nachkommen, beambten und unterthonen, auch sonst von Männiglichen, in allen und ieden hie nachgesetzen Puncten und Artiklen, mainungen und begreiffungen unverbrüchlich gelebt, nachgangen, darwider nit gehandelt, sondern diss alles wahr, stätt und vesst gehalten werde. ${ }^{\prime 5}$

Fürstliche Testatoren versuchten grundsätzlich ihre Erben in Bezug auf die im Testament getroffenen politischen Verfügungen auf andere Art und Weise an ihren letzten Willen zu binden. Mit der Intention einer rechtlichen Bindung des Nachfolgers durch ein Treuegelöbnis - etwa in Form der Handtreue - rückte der Testator seinen letzten Willen hingegen in die Nähe eines Erbvertrages. Diese Form gewährte dem Erblasser die Möglichkeit, seine letztwillige Verfügung an Auflagen zu knüpfen. Neben der eingeforderten Handtreue der männlichen Erben unternahmen Monarchen in der Testamentsurkunde durch Androhung von Flüchen zusätzlich noch außerrechtliche Bindungsversuche. ${ }^{6}$

Grundsätzlich griffen Habsburger Testamente beim Transfer von Herrschaftswissen und politischen und konfessionellen Richtlinien auf den Nachfolger in der Regierung auf Instruktionen in Testamenten älterer Generationen zurück. Dies offenbart das frühneuzeitliche fürstliche Generationenverständnis, das den Fürsten als Individuum im Gedächtnis der Linie erhielt, seine Individualität aber zugunsten der im Vordergrund stehenden wirkmächtigen Dynastie zu unterdrücken suchte und ihn primär als Verwalter der Tradition verstand. In diesem Kontext ist die Einordnung der Testamente als Medien der intergenerationellen und politischen Kommunikation von großer Bedeutung. Die Testamente

\footnotetext{
${ }^{5}$ Testament Kaiser Ferdinands II. vom 10.5. 1621, HHStA, Familienurkunden Nr. 1579/1,2, Filmrolle Nr. 12; fehlerhaft teilediert bei BEMATZIK, PHILIPPOVICH, Testament Kaiser Ferdinands II. 338.

${ }^{6}$ RICHTER, Fürstentestamente 164-187.
}

trugen wesentlich zum jahrhundertelangen Erhalt des linearen Generationenverständnisses der habsburgischen Dynastie bei. Darin, so zeigen die Testamente, lag ein wesentlicher Schlüssel zum dauerhaften Machterhalt im Hause Habsburg.

Im Folgenden sollen inhaltliche Besonderheiten wie etwa die konfessionellen Bestimmungen habsburgischer Testamente im Vergleich zu anderen reichsfürstlichen Verfügungen vorgestellt werden. Während sich in den Testamenten der männlichen Habsburger über Generationen hinweg neben dem eigenen Glaubensbekenntnis die Befehle zur Rekatholisierung und beginnende habsburgische Hausfrömmigkeit nachweisen lassen, spiegeln die weiblichen letztwilligen Verfügungen mit ihren Anweisungen zur Totenkleidung einen interessanten Aspekt der Sichtbarmachung der pietas Austriaca wider. In einem zweiten Teil wird die intergenerationelle Kommunikation durch Testamente am Beispiel der Auseinandersetzung Kaiser Franz' II./I. mit den letztwilligen Verfügungen von Franz I. Stephan diskutiert. Im dritten Teil steht kontrastreich das fiktive politische Testament Josephs II., das kurz nach dem Tod des Herrschers mit imaginären Bekenntnissen und Erklärungsmustern politischen Handelns an die Öffentlichkeit trat und damit Herrschaft aus dem dynastischen in den öffentlichen Bereich hob. Aus der intergenerationellen wurde eine - wenn auch fiktive Kommunikation zwischen Herrscher und Untertan über gute Herrschaft.

\section{Rekatholisierung und pietas Austriaca}

Ein Sterbender hatte vor seinem Ende drei Dinge zu erledigen: das Bekenntnis seines Glaubens, das Abendmahl sowie die Ordnung seiner weltlichen Angelegenheiten. Mit der Errichtung 
eines Testaments konnten zwei der genannten Notwendigkeiten abgedeckt werden. ${ }^{7}$ Nach der konfessionellen Spaltung traten in den fürstlichen Testamenten die Zugehörigkeit und das oft sehr ausführliche persönliche Bekenntnis des Herrschers zur jeweiligen Konfession an die exponierte Stelle früherer materieller Verfügungen der Jenseitsvorsorge. ${ }^{8}$ Glaubensbekenntnisse katholischer Fürsten etablierten sich bis weit in das 18. Jahrhundert ebenso fest in Testamenten wie bei protestantischen Reichsständen und dienten als schriftliches, in einer Rechtsurkunde fixiertes, persönliches und öffentliches Bekenntnis.

Die Frömmigkeit gehörte zur Herrschertugend aller Fürsten. Die Reformation löste jedoch im Haus Habsburg die Überzeugung aus, einen besonderen Auftrag zur Gegenreformation erhalten zu haben. Um der frommen Tradition der Vorfahren willen wurden der alte Glaube und die Gegenreformation zu einem Hausgesetz der gesamten habsburgischen Dynastie erhoben. Dies spiegeln die Testamente habsburgischer Familienoberhäupter eindrucksvoll wider:

Kaiser Ferdinand I. hatte am 1. Juni 1543 in Prag sein zweites Testament errichtet und darin seinen festen Glauben an Gott bekundet sowie in Anlehnung an die Forderungen „Unsers lieben Herrn und Ahnherrn Kaiser Maximilian löblichen Gedächtnus Uns in seinem testament auferlegt hat, etlich [Klöster] zu errichten, daran bisher zu Unserm theil es etlichen Antheils vollziehung beschehen ist." Zugleich trug er seinen

\footnotetext{
${ }^{7}$ ARIÈs, Geschichte des Todes 245 und 252f.

8 Testamentarische Verfügungen betrafen vor allem Seelgerätstiftungen, die nach der Lehre der Verdienstlichkeit eines guten Werkes innerhalb der Jenseitsvorsorge den Erwerb ewigen und unvergänglichen himmlischen Lohnes garantierten. $\mathrm{Zu}$ Bayern vgl. RICHTER, Vor dem zeitlichen guet. Zu fürstlichen Seelenheilstiftungen im 15. Jahrhundert am pfälzischen Beispiel vgl. Alois GERLICH, Seelenheil und Territorium; JARITZ, Seelgerätstiftungen; BARTSCH, Seelgerätstiftungen im XIV. Jahrhundert.
}

Nachkommen auf, im alten Glauben zu verharren, „um Unser und ihr selbst Gewissen nit [zu] beschweren."

Sein Sohn, Erzherzog Karl II. Franz von Innerösterreich, errichtete zwei Tage vor seinem 45. Geburtstag im Jahre 1584, interessanterweise am gleichen Tag wie sein Vater, am 1. Juni, sein Testament. In seinem letzten Willen finden sich deutlichere gegenreformatorische Aspekte als in der Urkunde seines Vaters. Er kritisierte insbesondere die zahlreichen Konversionen der Reichsfürsten, zuweilen auch auf dem Sterbebett: „Vor allem aber, will nach absterben der menschen, sonderlich bey disen verwierten laidigen Zeiten allerley von derselben religion und glauben geredet, Also das zu mermallen auch die bewüssten wohlbekannten catholischen und höchsten Heupter der Christenheit, wie Gottselig und Christlich dieselben immer abgeleibt, bey den secten und kheczern dannocht dahin, als ob sy zur zeit ihres abscheides von irem hieuor bekhenten catholischen glauben abfallen und sich zu der neuen vermainten religion begeben, und nicht ohne sondere schmach der fromben abgestorbenen aufgeschrieben werden. ${ }^{\prime 10}$

Der alte Glaube sollte in der Dynastie der Habsburger fest verankert bleiben, weshalb es Erzherzog Karl auch darauf ankam, seine Töchter ausschließlich mit altgläubigen Fürsten zu verheiraten. Er befahl deshalb: „Souill aber die verheyrathung unserer lieben Töchter anlangt, ist unser will und mainung, das dieselben keinem andern, dann allein fürstlichen catholischen persohnen, so unserer waren uralen Römischen Religion in allem zugethon, verehelicht, Also man durch Gottes gnedigen Segen aine, oder mehr ratt und willen unserer liebsten Gemahl, wie auch der anderen nächsten freundt und

\footnotetext{
${ }^{9}$ HHStA, Familienurkunden Nr. 1255/1-3, Filmrolle Nr. 6.

${ }^{10}$ Eine vollständige Publikation findet sich bei HURTER, Ferdinand II.
} 
Gerhaben sich mit ainer fürstlichen Catholischen Person gehörtermaßen verheyrathen wuerde." 11 Gleiches galt für die konfessionelle Ausrichtung des Hofes. Bedienstete seien nach der katholischen Konfession auszuwählen, einzustellen und zu fördern: „Zu angeregter catholischer Religion, in derselben neben andern hohen Christlichen und weltlichen Potentaten stanthafft zuuerpleiben und bis in ir endt darin zuerharren, Solliches auch in Unseren landen $\mathrm{zu}$ erhalten, und das schödlich Sectisch wesen souill müglich aufczureiten, Sonder auch sich darin zubewarheiten, in iren Regierungen, auch $\mathrm{zu}$ Landtshauptmannschafte, verwesereyen, Vicsdomb: und andern Ämptern, Zu Hof, und sunst allenthalben in Landen die alten unsere getreue Diener (wofer sie darzue Zubewegen) und solliche Personen, so der alten waren Catholischen Religion seyen, Zunemben, und $\mathrm{Zu}$ gebrauchen, Darunter auch Unsere Catholische Landleit vor andern und frembden $\mathrm{Zu}$ bedenckhen." 12

In seinem Kodizill, das er neben diesen schon sehr ausführlichen testamentarischen Anweisungen zusätzlich dem Erhalt der katholischen Konfession widmete, schrieb er: „Zum andern. So werden auch In gedachtem Testament Unsere Erben und Söhne bey ainem Sonndern artikul, anlangent das Religion Weßen mit diesen Worten dahin vermant: das sy nach muglichkait verhuetten sollen, damit ausser der katholischen allein Seligmachenden Religion fremde und sectische nit gestatt noch gedult werden. (Diese zwey Wort nach muglichkait, so zweiflig und gleichsamb auf Wilkhür gestelt sein [...])."13

Karls Sohn, der künftige Kaiser Ferdinand II., hatte schon als Erzherzog von Innerösterreich in Loreto den Schwur entrichtet, den Katholizismus in all seinen Landen wieder zu etablieren.

\footnotetext{
${ }^{11}$ Ebd. 527.

${ }^{12}$ Ebd. 528.

${ }^{13}$ Ebd. 530.
}

Diese Intention ist auch in seinem Testament vom 10. Mai 1621 nachzuweisen, welches er zwei Jahre nach seiner Wahl zum Kaiser errichtete. Er eröffnete die Urkunde mit seinem Glaubensbekenntnis und schwor, dem alten, allein seligmachenden Glauben wie seine Vorfahren treu ergeben geblieben $\mathrm{zu}$ sein: ,[...] so bezeugen Wir hiermit, dass Wir keinen Glauben für den rechten und Säligmachenden hallten, dann denjenigen darinnen Wier von Unseren lieben hochgeehrten Voreltern gebohren und auferzogen auch bisshero mit mund, Herzen, auch allem Unseren thuen und lassen offentlich von Uns bekennet und aller menschlicher Möglichkeit nach mit dem und Unterthonen darzue gewisen worden seyn, das ist denn allten, allgemainen Catholischen, Apostolischen, Römischen glauben." 14

Mittels eines so eindrücklichen, im Testament verankerten Bekenntnisses des amtierenden Regenten sollte bei den Nachkommen eine Konversion zum Protestantismus vermieden und Kontinuität garantiert werden. Das Bekenntnis des Testators diente der Orientierung späterer Generationen und wollte zur Nachahmung animieren; denn die Konfessionen hatten fürstliche Familien und Dynastien gespalten, ihre Mitglieder zu Gegnern gemacht und damit funktionierende Einheiten zerstört.

Dem Testament legte der Monarch ebenso wie sein Vater noch ein Kodizill bei, das wie bei Erzherzog Karl als Ergänzung zur Testamentsurkunde noch einmal explizit und gesondert die Bewahrung des katholischen Glaubens forderte sowie geeignete Anweisungen zur Realisierung enthielt. Ziel war es, mit dem Kodizill seinen Nachfolger noch einmal ,[...] ganz vätterlich und innbrünstig zu vermahnen, dass sie inen

\footnotetext{
${ }^{14}$ HHStA, Familienurkunden Nr. 1579/1,2, Filmrolle Nr. 12. Fehlerhaft teilediert bei BeMATZIK, PHILIPPOPOVICH, Testament Kaiser Ferdinands II. 338. Die Punkte I bis III des Testaments finden sich publiziert bei HURTER, Ferdinand II. $635 \mathrm{f}$
} 
vor allen dingen angelegen sein lassen, unsere inen verlassene liebe Land und Leuthe bey unserem waaren, Apostolischen Römischen allain seligmachenden catholischen glauben zu erhalten, alle Secten und verführerische Leeren [sic!] und was zur Einschleichung deroselben Ursach, fürschub und anlass geben mag, alles Ennsts zu verhüetten und auszureuthen [auszurotten]. Und demnach unser vilgeliebter Herr Vatter, Erzherzog Carl säligster gedächtnus vilalegirtem seinen testament und vatterlicher disposition viel hailsambe Lehren und vermahnungen einverleibt, wie wier, als seine nachgelassene Kinder und Erben uns inn der Religion verhallten sollen, inmassen auch von anderen, unseren hochgeehrten Voreltern, sonderlich Kayser Ferdinando dem Ersten, mit unsterblichem Ruemb beschehen." ${ }^{15}$

Auffällig ist im Kodizill Ferdinands II. die starke Betonung der Glaubenstradition der Vorfahren sowie der Verantwortung des jeweiligen Regenten für deren Bewahrung. Dies entspricht der Tradition katholischer Häuser, in denen es die unverfälschte Glaubenstradition der Vorväter war, die mittels der Testamente beschworen wurde und die den Nachfolger auf den rechten Glauben festlegen sollte. Die gleichbleibende Konfession des Hauses Habsburg wirkte sich nicht zuletzt auch dynastisch identitätsstiftend aus und trug dabei nicht unwesentlich zur staatlichen Identitätsbildung bei. ${ }^{16}$ Aus diesem konfessionellen „Wir-Verständnis“ erwuchs für die Dynastie der Habsburger über Generationen hinweg eine spezifisch kulturelle und politische Identität. Diese pietas Austriaca spiegelt sich in den konfessionellen Bezügen und wörtlichen Anlehnungen an die Glaubensbekenntnisse der

\footnotetext{
${ }^{15}$ Kodizill vom 10. 5. 1621, HHStA, Familienurkunden Nr. 1579/1,2, Filmrolle Nr. 12.

${ }^{16}$ Wolfgang Weber hat bereits den Beitrag der dynastischen für die staatliche Identitätsbildung aufgezeigt und nachgewiesen. WEBER, Dynastiesicherung und Staatsbildung 103.
}

Vorfahren in den Testamenten sehr deutlich wider.

Ferdinand II. riet seinem Erben, seinen „Guberneuren" und späteren Generationen, wachsam zu sein und zu schauen, ob der katholischen Religion unzuträgliche Praktiken im Land nachzuweisen seien. In diesem Falle sollten sie mittels „deren von uns fürgeschriebenen und angefangenen oder auch anderen, nach gestalt der zeit und leuffden träglichen Mitteln dennselben steren und abwehren und sich nicht darvon abschrecken noch verhintern lassen, sondern sich darbey zu erinnern, dass es Gottes werk seye. [...] Dieweil auch zu diesem allem ein sehr vorträglich mittel ist, die geistlichkeit und Priesterschaft in Eeeren zu halten. ${ }^{\prime 17}$

Die ausführlichen konfessionellen Reflexionen und detaillierten Anweisungen zur Gegenreformation ließen in den späteren habsburgischen Generationen nach. Deutlich pragmatischer rückte die Konfession neben andere Bereiche herrscherlichen Schutzes. So legte Leopold I. in seinem zweiten Testament aus dem Jahr 1688 unter Punkt 28 allen seinen Söhnen, Töchtern, der Gemahlin, „dann gesambten meinen politischen und Militer=Bedienten; die Erhaltung der Ehr Gott[es], conservierung und Erweitterung unser allein seeligmachenden Römisch Cattolischen Religion, befürderung der Justiz, schutz und schirmb gesambter meiner Erbkönigraich und Landen und alle meine Unterthanen, wie auch die geistliche und religiosi" ans Herz. ${ }^{18}$ Maria Theresia schrieb in ihrem Testament vom 22. Juli 1767 ein eher formelhaftes Glaubensbekenntnis: dass „,...] Ich nach dem Beyspiell Meiner frommen Vor-Eltern in dem allein Seelig-Machenden wahren Römisch-Catholischen Glauben leben und sterben werde in der zuver-

\footnotetext{
${ }^{17}$ Kodizill vom 10. 5. 1621, HHStA, Familienurkunden Nr. 1579/1,2, Filmrolle Nr. 12.

${ }^{18}$ HHStA, Familienurkunden Nr. 1817/1-3, Filmrolle Nr. 15, fälschlicherweise als Konzept zum Testament von 1705 bezeichnet.
} 
sichtlichen Hoffnung, daß Meine arme Seele nach ihrem Abschied aus der Welt durch diesen heyl. Glauben aus unendlicher Barmherzigkeit Gottes zur ewigen Glückseligkeit gelangen werde. “19

Joseph II. verzichtete in seinem Testament aus dem Jahr 1781 schließlich ganz auf ein ausführliches Glaubensbekenntnis und begnügte sich damit, lapidar zu bemerken: „Meine Seele gehört dem Schöpfer; an meinem Körper ist nichts gelegen; als ein Diener des Staatts hab ich gelebet für denselben gewacht; alles gehoret also dem der durch die natürliche in Meinem hause eingeführte Erbfolge, mir am Throne folgen [...]." ${ }^{\prime 20}$ Anweisungen an den Nachfolger fehlen in diesem Testament ganz.

\section{Totenkleidung in habs- burgischen Frauentestamenten}

Nicht nur die männlichen Familienmitglieder trugen im 16. und 17. Jahrhundert den Gedanken der Gegenreformation und der "pietas Austriaca" der nächsten Generation an. Auch die Gemahlinnen übernahmen mittels ihrer Testamente eine wichtige Funktion in der öffentlichen Repräsentation habsburgischer Frömmigkeit.

Einer Fürstin kam in der Frühen Neuzeit traditionell die Funktion des Vorbildes gelebter Frömmigkeit und Tugendhaftigkeit $\mathrm{zu}$, die sich aber seltener äußerlich in Form von Bildern als vielmehr in frommen Stiftungen oder durch ihren Lebenswandel offenbarte. Dem ernsten Willen, ihr weltliches Wirken als Dienst an Gott verstanden wissen zu wollen und den Dienst im Tode noch direkter fortzusetzen, verliehen verehelichte Habsburgerinnen vereinzelt auch

\footnotetext{
${ }^{19}$ Maria Theresia hinterließ acht letztwillige Verfügungen. Das Testament vom 22. 6. liegt im HHStA als Familienurkunde Nr. 2006.

${ }^{20}$ Eigenhändiges Testament vom 21.5. 1781, HHStA, Familienurkunden Nr. 2101/1,2, Filmrolle Nr. 20.
}

dadurch Ausdruck, dass sie auf dem Sterbebett einem Orden beitraten und sich im geistlichen Habit beisetzen ließen.

Im Haus Habsburg gehörte der Ordenshabit für die weiblichen Mitglieder zwar nicht zur Begräbnistradition, doch fällt auf, dass sich zwischen dem 16. und dem beginnenden 18. Jahrhundert nur wenige Frauen wie Leopoldina (1632-1649), die zweite Gemahlin Kaiser Ferdinands III., in einem aufwendigen Hofkleid, mit einer Krone auf dem Kopf sowie weiteren Insignien einer Kaiserin aufbahren und beisetzen ließen. ${ }^{21}$ In der Regel wählten die Kaiserinnen die Tracht einer Bruderschaft oder eines Ordens, dem sie entweder durch Mitgliedschaft zu Lebzeiten oder durch Stiftungen verbunden waren. Ihre Vorstellungen von einem Ordenshabit als Totenkleid fixierten die Habsburgerinnen in ihren Testamenten und begründeten darin auch zumeist ausführlich ihre Wahl.

Kaiserin Eleonora Magdalena (1655-1720), geborene Herzogin von Pfalz-Neuburg und dritte Gemahlin Kaiser Leopolds I., war als Prinzessin streng katholisch erzogen worden und wünschte eigentlich, obgleich sie die älteste Tochter ihrer Eltern war, in ein Kloster einzutreten. ${ }^{22}$ Die Ehe mit dem Kaiser ging sie nur schweren Herzens ein. Sie führte - trotz ihrer außergewöhnlichen politischen Aktivitäten als vertraute Beraterin ihres Mannes und spätere Regentin der Österreichischen Erblande - am Wiener Hof ein äußerst zurückgezogenes, fast klösterlich anmutendes Leben. Während einer Beichte erlitt sie einen Schlaganfall und verstarb einige Wochen später im Jahre 1720.

Bereits Jahre zuvor hatte sie ein Testament errichtet, in dem sie regelte, wie sie vor Gott zu treten gedachte. Sie schrieb: "Ich Eleonora Magdalena: Allen Menschen von Gott zu stre-

\footnotetext{
${ }^{21}$ HAWLIK-VAN DE WATER, Der schöne Tod 93.

${ }^{22} \mathrm{Zu}$ Kaiserin Eleonora Magdalena vgl. LeITGEB, Frauen am Kaiserhof 65-72; ADERHOLD, Eleonore Magdalena Theresia.
} 
ben auferlegt worden und so gewiß selbiges ist also ungewiß [ist] die Zeit und Stundt, habe mich entschlossen demnach bey gutter gesundtheit und Vernunfft meinen letzten Willen hiermit aufzusetzen wie volgt: Erstlich befehle ich meine arme Seele und meinen armen Cörper Gott dem herrn und Erlößer, der sie durch seinen heil. Leib und Blut durch sterben erlößt hatt, dem Hl. Geist der sie geheiliget hatt. Ich befehle sie der Wahrheit der Hl. Mutter Gottes Maria, des Hl. Josephs, Hl. Michael füglich allen Patronen und allen Heiligen Gottes, damit ich die Vergebung so vieller begangener Sünden und vor dem gerechten Richter so gnädige Urteil erlangen möge in Ewigkeit, Amen. Mein Leib soll nicht außgezogen oder gewaschen, vielweniger balsamirt werden [,] sondern über das wenige was ich in stroh angehabt das schon verfertigte Totenkleidt der Grauen Bruderschafft angeleget werden. Ein höltzerner Rosenkranz soll mir in der handt gelaßen werden. ${ }^{23}$ Für ihren Sarg wünschte sie sich die Aufschrift: „Eleonora Magdalena arme Sünderin“.

Bereits in der Einleitung ihres Testaments wird deutlich, dass sie auf ihre Würde als Kaiserin und Erzherzogin von Österreich keinen Wert legte. Vielmehr wünschte sie, als arme Sünderin vor Gott zu treten, die nicht nur ohne fürstliches Gepränge beerdigt werden wollte, sondern zur Läuterung ihrer Sünden und zum Bekenntnis ihrer Frömmigkeit als Totenkleid die Kutte der „Gesellschaft [von] deren Durchläuchtigst und Hoch=Adeligen sogenannten Sklavinnen derer leibeigenen Dienerinnen Mariens" wählte. Sie entsagte damit allen weltlichen Würden und vergänglichen Dingen. Ihre Hinwendung zu einem Orden im Tod stellte eine Erfüllung und Konsequenz ihres frühesten Lebenswunsches und ihrer Lebensführung dar, hatte sie doch bereits zu Lebzeiten die vollkommene Hingabe

${ }^{23}$ Testament der Kaiserin Eleonora Magdalena, HHStA, Familienurkunden Nr. 1859-1861. ihrer Freiheit an Maria gelobt. Obwohl sie auf jeden üblichen Hinweis auf ihren Status als Kaiserin und ihre Zugehörigkeit zum Haus Habsburg verzichtete, stand ihre Entscheidung für einen Ordenshabit dennoch nicht im Gegensatz zu den Traditionen der Dynastie, sondern vielmehr sogar im Einklang mit der "pietas Austria$c a^{\prime \prime}$, der einzigartig propagierten Frömmigkeit und Marienverehrung der Familie ihres Gemahls. Der Marienkult war im 16. Jahrhundert aus Spanien übernommen worden und erreichte im 17. sowie in der ersten Hälfte des 18. Jahrhunderts unter dem Einfluss der Jesuiten seine größte Blüte am Wiener Hof. Eleonora Magdalenas Gemahl, Leopold I., hatte nach seiner Kaiserkrönung der habsburgischen Hauspatronin Maria in Altötting als seiner „höchsten Kaiserin“ den Lehnseid geschworen.

Kaiserin Eleonora Magdalena konnte mit der Wahl des Ordenshabits als Totenkleid nicht nur ihre persönlichen Vorstellungen von der äußerlichen Bekundung ihres unerschütterlichen Glaubens mit den Erwartungen des Hauses Habsburg an eine Fürstin sehr gut verbinden. Sie folgte auch dem Vorbild ihrer Vorgängerin, der zweiten Gemahlin Leopolds I., Claudia Felicitas (1653-1676), die sich auf eigenen testamentarischen Wunsch in "habitu st. Dominici", der Ordenstracht der Dominikaner, hatte beisetzen lassen, ${ }^{24}$ während sich seine erste Frau, Kaiserin Margarita Teresa (1651-1673), in weltlicher Prunkkleidung, einem „plumeran farben goldtstuck deroselben angezogenen Klaidt mit einer weissen Hauben über den Khopf" hatte aufbahren und beerdigen lassen. ${ }^{25}$ Auch Eleonora Magdalenas Nachfolgerin, Kaiserin Amalia Wilhelmina, die Gemahlin Josefs I., wurde bereits zu Lebzeiten in der Ordenstracht des von ihr gegründeten Salesianerinnenklosters porträtiert und ihrem testamentarischen Wunsch gemäß im

\footnotetext{
${ }^{24}$ HAWLIK-VAN DE WATER, Der schöne Tod 98.

${ }^{25}$ Ebd. 95.
} 
Jahr 1711 auch in diesem Habit unter dem Hochaltar des Klosters beigesetzt. ${ }^{26}$

Es lässt sich nach dem Vergleich der Einkleidungsgewohnheiten der kaiserlichen Gattinnen am Wiener Hof feststellen, dass zwischen 1640 und 1740 die meisten Kaiserinnen in ihren letztwilligen Verfügungen ein Ordensgewand als Totenkleid wünschten. Allerdings bestand zur Wahl eines geistlichen Habits kein Zwang durch das habsburgische Sterbezeremoniell. Es lag vollkommen im Bereich der persönlichen Entscheidung der kaiserlichen Gemahlin, eine weltliche oder geistliche Robe für ihren letzten Gang festzulegen. Bei der mehrheitlichen Entscheidung für eine Ordenstracht mag aber das Verhalten der Vorgängerinnen eine große Rolle gespielt und dies somit die eigene Entscheidung mitgeprägt haben. Friedrich Carl von Moser unterstellte als protestantischer Autor in seinem "Teutschen Hofrecht" 1754 den habsburgischen Kaiserinnen bei der Entscheidung für das Ordenskleid zudem die persönliche Hoffnung, im Jenseits einen Teil der Sünden erlassen zu bekommen und Gott zu gefallen. ${ }^{27}$

Wurde ein Ordenshabit gewählt, so präsentierte sich die verstorbene Kaiserin noch einmal vor ihren Verwandten und dem Hofstaat als ausgewählter Öffentlichkeit den allgemeinen Vorstellungen gemäß, die mit der Rolle einer Herrscherin verbunden waren, vorbildhaft, als fromme Frau und tugendsame Fürstin. Zudem war der Ordenshabit ein äußerlich sichtbares Bekenntnis zum dynastisch geprägten Marienkult des Hauses Habsburg.

${ }^{26}$ Ebd. 96.

${ }^{27}$ MOSER, Teutsches Hofrecht, 408.

\section{Die Kenntnis politischer Instruktionen als dynastisches und politisches Band}

Kaiser Franz I. Stephan errichtete am 14. Dezember $1752 \mathrm{zu}$ seinem Testament vom 28. Januar 1751 ein Kodizill. Diesem legte er die eigenhändig verfasste "Instruction pour mes enfants" bei. Er sah diese Abhandlung als „Vermahnung" und damit seine letzte väterliche Pflicht bzw. letzte Erziehungsleistung an, weshalb er auch noch einmal allen seinen Kindern die Liebe zu Gott und zur katholischen Religion ebenso wie die "Gloire“ der Monarchie und habsburgischen Dynastie ans Herz legte sowie über das fürstliche Dasein und sein Verständnis von Herrschaft reflektierte. Er befahl seinen Kindern, die Weisungen zwei Mal jährlich zu lesen.

Testament, Kodizill und „Instruction“ ließ er im Hausarchiv aufbewahren. ${ }^{28}$

Nach seinem Tod am 18. August 1765 fand die übliche Testamentseröffnung ${ }^{29}$ statt, deren $\mathrm{Ab}$ lauf vor einer begrenzten familiären und höfischen Öffentlichkeit durch ein Protokoll vom 9. Oktober des gleichen Jahres dokumentiert ist. Danach wurden durch Fürst Kaunitz-Rietberg folgende Papiere in ein Portefeuille gelegt:

- Das originale Testament vom 28. Januar 1751,

- das Kodizill von 1752 mit der „Instruction“,

- drei Gutachten Kaunitz' und des Reichshofrates von Stetter über das erwähnte Testament,

- das originale Konferenz-Protokoll vom 9. Oktober 1765 mit zwei eigenhändigen Voten des Reichs-Vize-Kanzlers

\footnotetext{
28 „Die gecrönten Häupter pflegen die von ihnen verfertigten Testamenta mit besonderen Solennitäten, [...] in ihre Reichs=Archiva beylegen lassen", vermerkte RoHR, Ceremoniel-Wissenschafft, 1. Theil, Cap. XVII, § 13, 296.

${ }^{29}$ Zum allgemeinen Ablauf von Testamentseröffnungen vgl. RICHTER, Fürstentestamente 118-150.
} 
- sowie die geistlichen Betrachtungen der spanischen Infantin Maria Isabella.

Handschriftlich notierte Kaunitz-Rietberg darauf, dass die lederne Mappe ohne „höchsten befehl nicht eröffnet werden" dürfe. ${ }^{30}$

Das Portefeuille Franz Stephans und die Vermerke der Geheimhaltung beweisen einmal mehr den zeitlichen Entstehungszusammenhang fürstlicher Testamentsurkunden und zusätzlicher Denkschriften. Die Instruktionen ergänzten oder vertieften die appellativen Teile der fürstlichen Testamente. In der Regel nahmen sie ebenfalls Bezug auf die Dynastiepolitik wie auf innere und äußere Belange der Landespolitik. Die Betonung ihres Status als Geheimschriften durch die Verfasser und die unzugängliche Verwahrung bei den Testamenten waren gerechtfertigt, weil sie dem Erben oft über die Informationen im Testament hinaus wesentlich ausführlicher und direkter eigene Erfahrungen und subjektive Ansichten zu einzelnen politischen Sachverhalten vermittelten. Schließlich kam es nach Moser darauf an, dass „die Arcana des Hauses nicht zu vil proparliret werden". ${ }^{31}$

Dem gegenüber sollten die Testamentsinhalte der Vorgänger von den Nachkommen regelmäßig zur Kenntnis genommen werden. In einigen Häusern wie Hessen-Darmstadt wurden fürstväterliche Testamente am Sterbetag noch einmal verlesen, manchmal passagenweise auch für Nachkommen kopiert und regelmäßig zur Errichtung des eigenen Testaments herangezogen. ${ }^{32} \mathrm{Ob}$ der letzte Wille des Kaisers oder die Instruktion an seine Kinder außerhalb der Testamentseröffnung im 18. Jahrhundert noch einmal zur Kenntnis genommen wurden, ist unklar. Es fehlen entsprechende Vermerke.

\footnotetext{
${ }^{30}$ HHStA, Familienurkunden Nr. 1954/1, Filmrolle Nr. 17.

${ }^{31}$ Moser, Neues Teutsches Staats=Recht 13, 3. Buch, 64. Kap. § 26, 487.

32 RICHTER, Fürstentestamente 160-191.
}

Erst im 19. Jahrhundert stieß der Inhalt des Portefeuilles auf Interesse. Am 24. September 1824 wurde die Mappe auf Befehl des Kaisers Franz II./I. aus dem Archiv geholt, von ihm eröffnet und die Papiere von ihm gelesen sowie im Anschluss wieder versiegelt und reponiert.

Am 1. März 1830 wurde die Mappe auf „seiner K.K. Mayestät Allerhöchst mündlichen Befehl“ vom Staatssekretär Vincenz Pittrich eröffnet. Er hatte zum persönlichen Gebrauche des Kaisers Abschriften zu nehmen. Nach Vollendung der Kopien wurde am 7. Juli 1830 alles wieder versiegelt und verschlossen ins Archiv zurückgelegt. ${ }^{33}$

Es stellt sich natürlich die Frage nach den Anlässen, die Franz II./I. dazu veranlassten, das Konvolut der letztwilligen Verfügung und Instruktion seines Vorfahren zu öffnen und zur Kenntnis $\mathrm{zu}$ nehmen. Ein Grund konnte bisher nicht ermittelt werden. Anhaltspunkte geben jedoch folgende Überlegungen:

Interessant ist zunächst der zeitliche Kontext der Auseinandersetzung mit den Papieren Franz Stephans in den Jahren 1824 und 1830, dem Jahr der Julirevolution. Das multiethnische Vielvölkerreich Österreich sah sich insbesondere seit den 1820er Jahren als Gesamtstaat bedroht, erwies sich doch die prinzipienpolitische Kooperation der europäischen Großmächte als Fiktion. Michael Hochedlinger verwies kürzlich darauf, dass die Dynastie, das stehende Heer, die Bürokratie und die katholische Kirche Identifikations- und Bezugspunkte für das gesamte Reich boten. ${ }^{34}$ Gerade das dynastische Moment erscheint in dieser Krise von besonderer Bedeutung. Die Habsburger sahen sich im Vergleich $\mathrm{zu}$ anderen reichsständischen Familien nicht als einen üblichen Generationenverband, der Ideen und Vorstellungen von Konfession und Herr-

\footnotetext{
${ }^{33}$ ReINÖHL, Politisches Vermächtnis Franz' I. 74, Anm. 12, Schreiben Metternichs an Münch; HOKE, Kaiser 111-123.

${ }^{34}$ HochedLINGER, König und Habsburgermonarchie 5.
} 
schaft über Jahrhunderte tradierte, sondern als höchstes Haus, das den wahren Glauben als Herrschaftslegitimation und Herrschaftsziel hütete. ${ }^{35}$ Durch diese überzeitliche Mission hatte der Chef des Hauses Habsburg als Kaiser des Heiligen Römischen Reiches oder Österreichs ebenfalls über alle politischen Veränderungen der Zeit hinweg den Nationen und Ständen des einen oder anderen Reiches Garant eines imperialen Konsenses zu sein. Von diesem traditionellen Herrschaftsverständnis, das hinter jeder Forderung der Zeit in den 1820er und 1830er Jahren zurückblieb, war auch Franz II./I. beseelt. Es erscheint aus diesem Kontext logisch, dass der Kaiser des Übergangs, des Alten und neuen Reiches sich mit eigenhändigen Dokumenten zur Herrschaftsauffassung seiner großen Vorgänger auseinandersetzte. Dass er dabei auf die Papiere Franz Stephans zurückgriff, ist vor dem Hintergrund der zeitgleichen Stilisierung von Maria Theresia als mater Austriae und damit als Integrationsfigur aufgrund des ihr eigenen Konservatismus $^{36}$ und politischen Erfolgs im Vergleich zu ihrem Sohn Joseph II. verständlich.

Die Testamente der Vorfahren verloren durch dauerhafte Präsenz und inhaltliche Bezugnahme im eigenen letzten Willen nicht an Aktualität. Das letzte Wort des Ahnen erhielt und behielt Gewicht, minderte dennoch die eigene Herrscherautorität von Franz II./I. nicht, denn sein eigenes politisches Handeln hatte für ihn nur im Konsens mit den Vorfahren und als stringente Weiterführung von deren Herrschaft zu geschehen. Dieses Prinzip des angestrebten Konsenses der Generationen und die immer wiederkehrende Bestätigung des Althergebrachten hatten einst geholfen, den erreichten dynastischen und politischen Status der Habsburger zu konservie-

\footnotetext{
${ }^{35}$ Vgl. dazu EvAns, Die Habsburger 121-145; РОКОМY, Clementia Austriaca 207-215; STRAUB, Drei letzte Kaiser.

${ }^{36}$ Darauf verweist ebenfalls HocHEDLINGER, König und Habsburgermonarchie 6.
}

ren und auszubauen. Franz II/I. wollte diese erfolgreiche Strategie nicht durch aufkommenden Individualismus ändern.

Diese konservative und stark dynastisch geprägte Auffassung gab er auch an seinen Sohn und Erben weiter. Das politische und das kirchenpolitische Handschreiben vom 28. Februar 1835, die beide auf dem Sterbebett entstanden und mit dem am 1. März verfassten Testament ein Konvolut ergaben, basierten offenbar auf langer Vorbereitung. Metternich bekannte, dass diese Vermächtnisse mehrfach besprochen und festgesetzt worden seien. ${ }^{37} \mathrm{Zu}$ dieser Vorbereitung mag möglicherweise auch der Blick in das Testament und die Instruktion Franz Stephans gehört haben.

Auch die vielzitierte Weisung im Handschreiben vom 28. Februar 1835 an den Erstgeborenen und Erben, Erzherzog Ferdinand, „verrücke nichts an den Grundlagen des Staatsgebäudes, regiere und verändere nicht", passt in den Kontext der von Franz II./I. vertretenen Aufgabe der Traditionswahrung und nimmt Bezug auf das von den Vorfahren vorgegebene katholische Herrschaftsverständnis.

Das Bestreben, einer neuen Generation die politische Handlungsfreiheit beschneiden zu wollen, ist ein Charakteristikum der Monarchie. Die Haltung, die Nachfolger an die Tradition zu binden, stand jedoch in den 1830er Jahren längst in der Kritik. Friedrich Carl von Moser hatte schon 1788 in seiner Einleitung zur Publikation des Testaments des Großen Kurfürsten im „Patriotischen Archiv für Deutschland“ Kritik an der fürstlichen Vermessenheit geübt, mittels Testamenten politisch und konfessionell zu instruieren. Er schrieb: Es ist „,[...] an sich schon Schwachheit des Menschlichen Stolzes, über

\footnotetext{
${ }^{37}$ REINÖHL, Politisches Vermächtnis Kaiser Franz' I. 75 .
} 
sein Lebens=Ziel hinaus herrschen, gebieten und Gesetzgeber seyn zu wollen.“ “38

Die Testierfreiheit wurde daher im 19. Jahrhundert in die Kritik an der Willkürherrschaft des Ancien Régime einbezogen und ihre Einschränkung im Kontext der französischen Verfassung angemahnt. In der Deklaration der Menschenrechte aus dem Jahre 1793 heißt es, dass keine Generation das Recht haben solle, eine zukünftige Generation den eigenen Gesetzen zu unterstellen. In einem Dekret aus dem Jahre 1794 wurde die Testierfreiheit deshalb ganz aufgehoben. ${ }^{39}$ So verwundert es nicht mehr, dass Thomas Paine in seiner Schrift "Rights of Man" (1791) für eine Demokratie politische Handlungsfreiheit forderte, sowohl für die eigene als auch für die künftigen Generationen. Paine warnte das Parlament und seine Mitglieder vor der Überheblichkeit, mittels Gesetzen über den Tod hinaus regieren zu wollen: „Immortal Power is not a human right and therefore cannot be a right of Parliament. The circumstances of the world are continually changing, and the opinions of men change also; and as government is for the living, and not for the dead, it is the living only that has any right in it." 40 Damit gestand er jeder neuen Generation das Recht eines politischen Neuanfangs zu, das in der Monarchie dynastischer Tradition zum Opfer fiel.

Als Reaktion auf die starken politischen Veränderungen Ende des 18. Jahrhunderts nahmen in den reichsfürstlichen Dynastien die Dichte politischer Verfügungen in Testamenten sowie die Bezugnahme auf Verfügungen der Vorgänger deutlich ab. Ein Beispiel ist das oben angeführte Testament Josephs II. vom 21. Mai 1781. Nicht

\footnotetext{
${ }^{38}$ Einleitung zur Edition des Testaments Kurfürst Friederich Wilhelms von Brandenburg vom 20.3. 1688. Vgl. Moser, Ungedrucktes Testament Friderich Wilhelms des Großen Churfürstens 139.

${ }^{39}$ FonteTtE, Grandes dates du droit 17-20.

${ }^{40}$ WILDT, Generation als Anfang 160-164; PAINE, Rights of Man 281.
}

mehr das Traditionsbewusstsein half den Familien ihre Macht zu erhalten, sondern die Einsicht in die Wandelbarkeit der Welt, die eine kurzfristige Anpassung erforderte, führte auch unter den Reichsfürsten zur Beschränkung der eigenen Wirksamkeit auf die eigene Lebenszeit. Bei den Habsburgern ist das, wie am Beispiel Franz II./I. gezeigt werden konnte, signifikant anders. Josephs Neuerungen und der Bruch mit den Traditionen, die sich auch an der ungewöhnlichen Kürze seines Testaments zeigen, hatten zum Scheitern geführt. Erst der konservativere Kurs seines Bruders Leopold hatte die Krise behoben. Somit war und blieb die Tradition und mit ihr die Geschichte auch im 19. Jahrhundert Magistra vitae dynastischen und politischen Handelns sowie dynastischer und politischer Verpflichtung jeder einzelnen Herrschergeneration.

\section{Fürstliche Arkana in der Öffentlichkeit?}

In den Jahren 1790 und 1791 erschien zuerst in Brüssel und dann in Wien das Testament politique de l'Empereur Joseph Second, Roi des Romains als zweibändige Ausgabe. Die Schrift wurde sehr schnell als nicht authentischer Text des Kaisers entlarvt. Joseph Marie Quérard schrieb im zweiten Band seiner Les supercheries littéraires dévoilées: "Sur le titre seul, on soupçonnera que c'est ici une de ces suppositions si multipliées depuis le Testament, vrai ou faux, du cardinal de Richelieu, et dès qu'on en aura lu quelques lignes on n'en doutera plus. ${ }^{41}$

Schon Zeitgenossen stellten berechtigt die Frage nach dem Autor des Textes. August Hennings und Ernst Christian Trapp, die Herausgeber des "Schleswig'schen und ehemals Braunschweigischen Journals" waren kritisiert worden, dass sie

${ }^{41}$ QUÉRARD, Supercheries littéraires dévoilées 419. 
aus dem so genannten politischen Testament ${ }^{42}$ des verstorbenen Kaisers einige Teile ins Deutsche übersetzt abgedruckt hatten, ohne dass der Nachweis der Authentizität erbracht worden war. ${ }^{43}$ Hennings hatte in der Tat die Echtheit nicht thematisiert, sondern sich vielmehr jeglicher Bewertung enthalten. Nun führte er zur Verteidigung einen argumentativen Feldzug für die Authentizität seiner Quelle und bezog sich dabei auf die offensichtlich üblichen Dementi und Widerrufe von Herrscherhäusern gegen Falschmeldungen in Zeitungen und Zeitschriften: „Lassen sich doch die größten Höfe Europens fast in allen Zeitungen herab, Gerüchten und Vorspiegelungen, die oft von viel geringerem Belang, die oft von der Art sind, daß ihre

${ }^{42}$ Zur Gattungsdefinition mit Hinweisen auf ältere Definitionen vgl. neuerdings RICHTER, Fürstentestamente 439ff.

${ }^{43}$ Merkwürdige Stellen. Dem Bildungsstreben sowie dem politischen und gesellschaftlichen Interesse des aufgeklärten Bürgers und der Obrigkeit, die sich den Aufklärungstendenzen gegenüber offen zeigte, kamen gegen Ende des 18. Jahrhunderts zahlreiche Monatszeitungen entgegen. Beispiele sind August Schlözers Staats-Anzeigen (1782-1795), Friedrich Carl von Mosers Patriotisches Archiv für Deutschland (1784-1790), das Göttingische Historische Magazin (1787-1794), herausgegeben von dem Historiker Ludwig Timotheus Spittler und dem Philosophen Christoph Meiners oder Ernst Christian Trapps und August Hennings Schleswig'sches, ehemals Braunschweigisches Journal (1792-1793). Sie boten ihren Lesern aktuelle wissenschaftliche Diskussionen zur Geschichte und ihrem Umfeld, d.h. zur Theologie, zur Pädagogik und den schönen Künsten sowie den Staatswissenschaften. Großen Wert legten die Herausgeber bei der Auswahl der historischen Schriftstücke auf die Authentizität und damit auf die Verwendung von ,[...] so viel als möglich reine[n] Quellen“. Zit. n. Ludwig Timotheus Spittler, in: PÜTTER, Gelehrten-Geschichte 173. Das Braunschweigische Journal und sein schleswig'scher Nachfolger galten als eine der schärfsten und kompromisslosesten Zeitschriften des 18. Jahrhunderts, der die brisanten pädagogischen und politischen Schriften immer wieder von Lesern und Zensurbehörden vorgeworfen wurden. SCHMITT, Vernunft und Menschlichkeit 371 und 380. Zur preuBischen Zensur vgl. SchumanN, Berliner Presse.
Wahrheit oder Unwahrheit binnen einigen Tagen ganz von selbst ans Licht kommen muß, zu widersprechen. ${ }^{\prime 4}$ Da seine Publikation aus Wien jedoch in keiner Weise kommentiert worden sei, ging Hennings von der Echtheit aus: „Ich konnte also auch durch jene Betrachtung nicht bewogen werden, das Testament für untergeschoben zu halten. ${ }^{45}$

Danach wandte sich Hennings als Antwort auf den anonymen Vorwurf aufrührerischer Gesinnungen wegen der auffallendsten und gefährlichsten Stellen dieses angeblichen politischen Testaments ${ }^{46}$ noch einmal seinen Intentionen der „Bekanntmachung eines solchen Buchs in diesem Journale zu. Und wozu die Mittheilung einiger, und zwar so auffallender Bruchstücke aus dem selben? ${ }^{\prime 47}$ Hennings verteidigte sich damit, dass gerade die Passagen, in denen sich der imaginäre Joseph zu seinen Reformen der Kirche, seinen Gedanken zur militärischen Reichsverfassung und zur Rolle der Soldaten gegenüber dem Vaterlande äußerte, die „Nützlichsten" für ihn gewesen seien. Die Ausschnitte sollten den Leser belehren, zugleich aber auch die lesende Öffentlichkeit zum wertenden Richter über die Regierungsleistungen eines erst kürzlich verstorbenen Monarchen machen. Hennings verlieh dabei seinem Wunsch nach der Einschätzung von Josephs Werk unverhohlen Ausdruck: Er hoffe, mit dem Ausschnitt zu erreichen, dass eine „unparteiische Nachwelt mehr Gerechtigkeit wiederfahren lassen wird, als seine undankbaren Zeitgenossen“. ${ }^{48}$

Der Leser, in Kenntnis darüber gesetzt, dass dieses politische Vermächtnis von Anfang an für die Öffentlichkeit bestimmt gewesen sei, wird im ersten Ausschnitt von Hennings Publikation

\footnotetext{
${ }^{44}$ Hennings, Angebliches politisches Testament Josephs II 373.

${ }^{45}$ Ebd. 374.

${ }^{46}$ Ebd. 377.

${ }^{47}$ Ebd. 376.

${ }^{48}$ Merkwürdige Stellen 456.
} 
mit den angeblichen kritischen Reflexionen Josephs II. zum Stand und zur Aufgabe der Monarchen konfrontiert. Während der herrscherliche Ruhm nur eine Seifenblase und die Regierung vieler Fürsten der Quell von Elend seien, mache der Tod alle Menschen gleich, lösche jedoch nicht das unheilvolle Wirken der Toten aus. Es müsse deshalb das Ziel von Herrschaft nach dem politischen Testament im Abstellen des Elends und im Beglücken liegen. ${ }^{49}$ "Ich bedaure den Thron nicht; über diesen Punkt bin ich sehr ruhig; aber ich leide, daß ich bey aller angewandten Mühe, das Gute zu bewirken, nur so Wenige glücklich und so Viele mißvergnügt und undankbar sehe. Ich habe die Menschen nicht genug gekannt. Meine Absichten waren redlich [...]. “50 Nun lagen des Kaisers Gedanken auf eigenen Wunsch dem "Urtheile der Welt" vor. ${ }^{51}$ Der Monarch bekannte, „mit zu vielem Eifer und durch nicht genug überlegte Mittel, die übermäßige Gewalt der Kirche in bedenklichen Zeiten angetastet zu haben". ${ }^{2}$

Die Preisgabe von herrscherlichem Arkanwissen $^{53}$ und die kritischen Selbstreflexionen in dieser Schärfe und Ausführlichkeit so kurze Zeit nach dem Tod Josephs II. mussten das zeitgenössische Lesepublikum zu Recht zweifelnd fragen lassen: „Ist es auch nur wahrscheinlich, daß Joseph so gedacht und gar so geschrieben haben sollte?“54 Publizierende Monarchen waren zwar keine Seltenheit mehr, aber die kritische Bilanz eigener Regierungsleistungen blieb im Urkundentestament oder einer ergänzenden Schrift - geschönt oder ungeschönt - zumeist

\footnotetext{
${ }^{49}$ Ebd. 458.

${ }^{50}$ Ebd. 459.

${ }^{51}$ Ebd. 460.

52 Ebd.

${ }^{53}$ Vgl. Lemma: ,"arcana status“ in: ZEDLER, UniversalLexicon 2, 612; vgl. ebenso: Lemma „arcanum regium“ als königliches bzw. fürstliches Geheimnis, ebd. 92.

${ }^{54}$ HenNINGS, Angebliches politisches Testament Josephs II. 371.
}

nur Gott und dem Erben sowie den nachfolgenden herrschenden Generationen vorbehalten. Nur in der aus der Geschichte konstruierten Fiktion der "Gespräche im Reich derer Todten“ rechtfertigte sich so mancher Herrscher vor einem Amtskollegen oder Vorgänger der eigenen Familie zum lehrreichen und manchmal ergötzlichen Lesevergnügen seiner Untertanen viele Jahre nach seinem Tod. 55 Damit offenbarte sich dem Leser eine ähnliche, jedoch vollkommen fiktive Form intergenerationeller Kommunikation, wie sie real mittels fürstlicher Testamente oder mittels Denkschriften innerhalb der Herrscherfamilien geführt wurde.

Rechenschaft eigener Regierungsleistungen vor dem Untertanen und an den regierten Untertanen als Adressaten gerichtet, war hingegen ungewöhnlich. Unabhängig von der Authentizität des Textes setzte dieser Rechenschaftsbericht den Monarchen der Kritik oder zumindest der öffentlichen Bewertung aus. Der Dienst des „Diener[s] des Staatts", wie Joseph II. in seinem authentischen urkundlichen Testament aus dem Jahr 1781 sein Wirken beschrieb, konnte und sollte nun bewertet werden - von den Menschen, denen dieser Dienst galt und nicht nur von Gott, von dessen Gnaden er die Herrschaft ausübte.

Machten die Habsburger ihre Person und ihr Handeln in ihren Testamenten jahrhundertelang zum Gegenstand der eigenen Beobachtung und Kontrolle innerhalb der Generationen der Dynastie, so ging diese Schrift weit darüber hinaus und suggerierte dem Leser, Joseph II. stelle sich

\footnotetext{
${ }^{55}$ David Faßmann hatte beispielsweise zwischen 1718 und 1739240 „Entrevuen“ entworfen und die Gespräche zwischen Verstorbenen als moralische Belehrung konzipiert. Vgl. dazu noch immer DAMBERG, Totengespräche David Fassmanns; KASCHMIEDER, David Faßmanns Gespräche im Reiche der Toten; BÖNING, NAGEL, WEBER, Welteroberung durch ein neues Publikum; MILBERG, Deutsche moralische Wochenschriften; MARTENS, Die Botschaft der Tugend.
} 
dem Urteil aller Stände. ${ }^{56}$ Dem Leser gaukelte die Schrift vor, der Kaiser habe einen offensiven Schritt an die Öffentlichkeit gewagt und gebe nun eine Antwort auf zahlreiche Klage- und kritische Gelegenheitsschriften wie die eines Anonymus unter dem Titel „Was ich noch tun würde, wenn ich Kaiser wäre" (1787) oder Joseph Richters Traktat „Warum wird Kaiser Joseph von seinem Volke nicht geliebt?“ (1787). ${ }^{57}$ Der Kaiser hatte schließlich selbst in $\S 3$ der Zensurregeln aufgerufen, Kritiken zuzulassen, „wenn es nur keine Schmähschriften sind, sie mögen nun treffen, wen sie wollen, vom Landesfürsten an bis zum Untersten, sollen, besonders wenn der Verfasser seinen Namen dazu drucken läßt, und sich also für die wahrheit der Sache dadurch als Bürge darstellt, nicht verboten werden, da es jedem Wahrheitliebenden eine Freude sein muß, wenn ihm selbe auch in diesem Wege zukömmt." 58 Nun begab er sich scheinbar mit seinen Ansichten und Positionen in die politische Arena der Öffentlichkeit, um sie $\mathrm{zu}$ verteidigen und sein Regierungswerk nicht nur wie seine Vorfahren vor der eigenen Dynastie darzustellen und $\mathrm{zu}$ rechtfertigen.

Die Öffentlichkeit strebte diese Richterstellung auch zunehmend an: Franz Kratter beschrieb die Rolle der Presse in seinen „Philosophische[n] und statistische[n] Beobachtungen vorzüglich die österreichischen Staaten betreffend“: „In einem freien, wohlgebildeten Staat muß jede öffentliche Handlung so gut der Zensur der Publizität unterworfen seyn, als die Uibertretung [sic!] des Gesetzes dem Urtheilsspruch des Richters. Jede Handlung, die vermög ihrer Folgen

\footnotetext{
${ }^{56}$ Dies geschah zum einen über die Publikation in Buchform und zum anderen über die teilweise Publikation in Zeitschriften, über die ein größerer Leserkreis erreicht wurde.

57 WANGERMANN, Waffen der Publizität 34f.

${ }^{58} \S 3$ der Grundregeln des Zensurwesens. Publiziert in KROPATSCHEK, Handbuch 517f. Zur Zensur unter Joseph II. vgl. SASHEGYI, Zensur und Gottesfreiheit 15f.; Ebenfalls bedeutend RuIZ, Anno 1790 und 1792.
}

Einfluß auf die Gesellschaft hat, ist eine publike Handlung. [...] der Vater, der durch eine unnütze Erziehung den Staat mit unnützen Bürgern belästigt, der Beamte, der das Aerarium veruntreut, der Richter, der sich zu Ungerechtigkeiten kaufen läßt, der Gesetzgeber, der durch Strenge sein Volk drückt usw. Uiber [sic!] diese spricht die Publizität oft ein giltigerses [sic!] Urtheil als der Richter auf dem Richterstuhle. Sie [die Presse] unterrichtet durch Beispiele, überzeugt durch Gründe, schreckt durch Unerbittlichkeit $a b$, zeigt die Tirannei [...]; sie dient zur echten Quelle der Geschichte unsres Zeitalters und wird eine erhabene, mütterliche Lehrerin der Fürsten sowohl als der Untergebenen, aller Stände, aller Klassen der Gesellschaft. "59

Neuerdings sah sich die Öffentlichkeit als Vermittlerin von Herrschaftswissen und als Kritikerin herrscherlichen Handelns. Dies implizierte, dass über viele Generationen gehütete fürstliche Arkana zu einem öffentlichen Wissen gerieten, das jedermann zur Kenntnis und zum Urteil gelangen sollte.

Der fiktive Gang eines Monarchen in die Öffentlichkeit und die Einbindung der Untertanen als Adressaten seines imaginären politischen Vermächtnisses unterstützte den offensichtlich seitens der Untertanen gewünschten Prozess der zunehmenden „Vermenschlichung" des Herrschers von Gottes Gnaden Ende des 18. Jahrhunderts. Das so genannte politische Testament Josephs zeigte dem Untertanen einen Herrscher, der als Staatsbürger handelte, indem er von seiner Vernunft im Sinne Kants öffentlichen Gebrauch machte. Der patriotische Bürger sah es als seine Pflicht an, sein Amt und sein Wissen zum Wohl und zum Zweck des Staates einzusetzen. Dies implizierte neben der Beschäftigung mit öffentlichen Angelegenheiten insbesondere die Äußerung von Kritik oder Vorschlägen zur

\footnotetext{
${ }^{59}$ KRATTER, Philosophische und statistische Beobachtungen 4 .
} 
Verbesserung. Der Mensch sollte nicht nur als Zeitgenosse ein zufälliger, sondern zugleich auch ein verantwortungsbewusster Teil und Spiegel des unmittelbaren Zeitgeschehens sein. Die Äußerung von Kritik oder Vorschlägen geschah nicht zuletzt über Denkschriften in der Öffentlichkeit, die Joseph durch seine Zensurbestimmungen ja sogar befördert hatte. ${ }^{60}$ Nun nutzte der Monarch scheinbar selbst den Raum der Öffentlichkeit und erklärte sein Vorgehen. Das scheinbare politische Testament des Kaisers unternahm wie die Habsburger in der Realität mittels der urkundengebundenen Testamente innerhalb der Dynastie und vor Gott nun in der Öffentlichkeit gegenüber den Untertanen den Versuch, über die Erklärungen und Rechtfertigungen sein Werk über den Tod hinaus zu schützen und zu erhalten bzw. sein Reformprogramm zu befördern. Zugleich implizierte der Diskurs auch Veränderungen.

Das imaginäre politische Testament forderte allein durch seine Existenz die Herrschenden auf, Politik und Machtausübung aus dem familiären Kontext ihrer Dynastie in den der gesamten Öffentlichkeit und damit aller Stände $\mathrm{zu}$ verlegen. Das klassische urkundengebundene Herrschertestament, dem nicht selten noch zusätzliche Denkschriften beigefügt waren, war so bewies dieses Werk - zwecklos geworden. Die Ausübung von Herrschaft und Regierung ging alle und nicht nur die Herrscherfamilie etwas an. Damit war ein entscheidender Schritt in Richtung realer Partizipation an Herrschaft getan.

Das so genannte politische Testament Josephs hatte eine ganz andere Intention, als die Zeitschriften, die wenige, vor allem ältere Urkundentestamente aus dem 16. und 17. Jahrhundert als Fürstenspiegel zur moralischen Belehrung publizierten. Friedrich Carl von Moser begrün-

${ }^{60}$ Vgl. dazu Hattenhauer, Deutsches Beamtentum $167 f$. dete beispielsweise die Publikation des Testaments Herzog Wolfgangs von Neuburg und Zweibrücken aus dem Jahr 1568 in seinem „Patriotischen Archiv“ wie folgt: „Die Beherzigung der religiosen [sic!] und moralischen Grundsätze des vortrefflichen Fürsten überlasse ich der alleinigen eigenen Empfindung der Leser."61 Dabei erkannte Moser die große Nähe der Testamente zur Gattung der Fürstenspiegel: „Die Beyspiele nun der einen Lebens- und Regentenspiegel darstellenden Fürstlichen Testamente erweckten Bewunderung und Nachfolge [...]." ${ }^{\text {62 }}$ Als ein solch hehres Vorbild oder Ideal zu wirken, dies vermochte der fiktive Rechenschaftsbericht eines Monarchen, der sein Regierungswerk in vielen Bereichen als gescheitert ansah, nicht zu leisten. Aber er eignete sich dennoch zum Spiegel einer neuen, transparenteren Herrschaftsauffassung und brachte allein durch seine Existenz in öffentlichen Medien wie dem „Schleswig'schen Journal“ den öffentlichen politischen Diskurs von Anhängern und Gegnern der Reformen Josephs in Gang.

\section{Zusammenfassung}

Der Beitrag hat exemplarisch gezeigt, wie stark urkundengebundene Testamente in der habsburgischen Dynastie die Etablierung der allgemein bekannten konfessionellen und politischen Tradition mit der Fixierung und Weitergabe von Herrschaftswissen unterstützten. Die Habsburger sahen in Testamenten genau wie andere Reichsfürsten geeignete Medien intergenerationeller Kommunikation. Im Gegensatz zu anderen Häusern blieben sie aufgrund politischer Krisen wie der Auflösung des Heiligen Römischen Reiches und der Errichtung des österrei-

\footnotetext{
${ }^{61}$ Moser, Testament Pfalzgrafen Wolfgangs Herzogs zu Neuburg 8.

${ }^{62}$ Moser, Testament Friderich Wilhelms des Großen Churfürstens, Einleitung 148.
} 
chischen Kaisertums, die im 19. Jahrhundert zur Aufgabe alter und Übernahme neuer Rollen durch die Dynastie führten, sogar dieser geheimen Kommunikationsmöglichkeit länger treu als andere Häuser. Aus der Tradition schöpfte die Familie Kraft. Somit boten die Testamente der Vorgänger Orientierung und Hilfe, wie am Beispiel Franz II./I. nachgewiesen werden konnte. Doch die Öffentlichkeit forderte immer mehr Kenntnis von politischem Arkanwissen herrscherlicher Familien und zielte zunehmend auf Mitbestimmung und Partizipation der Untertanen. Das fiktive und vielfach veröffentlichte politische Testament Josephs II. stand somit in einem Kontrast zu den geheimen Fürstentestamenten, der zeigte, dass Regierung nicht nur die Regierenden, sondern auch die Regierten etwas angeht.

\section{Literatur:}

Christine ADERHOLD, Eleonore Magdalena Theresia, eine kurpfälzische Prinzessin als deutsche Kaiserin (Hausarbeit an der Pädagogischen Hochschule Kaiserslautern 1964).

Philippe ARIÈS, Geschichte des Todes (München 1982).

Robert BARTSCH, Seelgerätstiftungen im XIV. Jahrhundert. Ein Beitrag zur Geschichte des Testaments in Österreich, in: Festschrift für Karl von Amira (Berlin 1908).

Edmund BEMATZIK, Eugen von PHILIPPOPOVICH (Hgg.), Das Testament Kaiser Ferdinands II. in: Gustav TuRBA (Hg.): Die Grundlagen der pragmatischen Sanktion. Die Hausgesetze (=Wiener Staatswissenschaftliche Studien 11, Wien-Leipzig 1913) 335-355.

Holger BÖNING, Michael NAGEL, Johannes WEBER (Hgg.), Welteroberung durch ein neues Publikum. Die deutsche Presse und der Weg zur Aufklärung. Hamburg und Altona als Beispiel (Bremen 2002).

Wilhelm DAMBERG, Die politische Aussage in den Totengesprächen David Fassmanns. Ein Beitrag zur Frühgeschichte der politischen Zeitschrift (phil. Diss., Univ. Münster 1952).

Robert Evans, Die Habsburger. Die Dynastie als politische Institution, in: Arthur Geoffrey DiCKENS (Hg.), Europas Fürstenhöfe: Herrscher, Politiker und Mäzene 1400-1800 (Graz 1978) 121-145.

François DE FONTETTE, Les grandes dates du droit (Paris 1994).

Alois GERLICH, Seelenheil und Territorium. Testamentsrecht von Fürsten und Grafen im Spätmittelalter, in: Andreas KRAUS (Hg.), Land und Reich, Stamm und Nation: Probleme und Perspektiven bayerischer Geschichte. Festgabe für Max Spindler zum 90. Geburtstag (= Forschungsberichte Antike und Mittelalter 1, München 1984) 395-414.

Hans HatTENHAUER, Geschichte des deutschen Beamtentums (Köln-Berlin ${ }^{2} 1993$ ).

Magdalena HAWLIK-VAN DE WATER, Der schöne Tod. Zeremonialstrukturen des Wiener Hofes bei Tod und Begräbnis zwischen 1640 und 1740 (Wien 1989).

August HenNings, Noch ein paar Worte über das angebliche politische Testament Josephs II., in: Schleswigsches, ehem. Braunschweigisches Journal 2 (1792) 364-382.

Michael HochedLINGER, Der König und die Habsburgermonarchie. Oder: wie preußisch war Österreich im 18. Jahrhundert?, in: Friedrich 300 - Eine perspektivische Bestandsaufnahme 5 [http://www. 
perspectivi-

a.net/content/publikationen/friedrich300-

colloquien/friedrich-bestandsaufnahme/hoched

linger_habsburgermonarchie]

(abgerufen am: 16. 05. 2010).

Rudolf HOKE, Der Kaiser von Österreich und der Römische Kaiser, in: Wilhelm BRAUNEDER (Hg.), Heiliges Römisches Reich und moderne Staatlichkeit (= Rechtshistorische Reihe 112, Frankfurt am Main 1993) 111-123.

Friedrich Emanuel von HURTER, Geschichte Kaiser Ferdinands II. und seiner Eltern bis zu dessen Krönung in Frankfurt, Bd. 2 (Schaffhausen 1858).

Gerhard JARITZ, Seelgerätstiftungen als Indikator der Entwicklung materieller Kultur im Mittelalter, in: Materielle Kultur und religiöse Stiftung im Spätmittelalter (= Veröffentlichungen des Instituts für mittelalterliche Realienkunde Österreichs 12 = Sbb. der ÖAW, phil.-hist. Klasse 554, Wien 1990) 13-35.

Käthe KASCHMIEDER, David Faßmanns „Gespräche im Reiche der Toten“ (1718-1740). Ein Beitrag zur deutschen Geistes- und Kulturgeschichte des 18. Jahrhunderts (phil. Diss., Univ. Breslau 1934).

Diethelm KLIPPEL, Herrschaft, Testament und Familie. Rechtsgeschichtliche Koordinaten von Herrscherund Fürstentestamenten, in: Brigitte KASTEN (Hg.), Herrscher- und Fürstentestamente im westeuropäischen Mittelalter (= Norm und Struktur 29, KölnWeimar-Wien 2008) 15-34.

Franz KRATTER, Philosophische und statistische Beobachtungen vorzüglich die österreichischen Staaten betreffend, Bd. 1 (Frankfurt-Leipzig 1787).

Joseph KROPATSCHEK, Handbuch aller unter der Regierung des Kaisers Joseph des II. für die k.k. Erbländer ergangenen Verordnungen und Gesetze in einer systematischen Verbindung (Wien 1785).

Hildegard LeITGEB, Frauen am Kaiserhof zur Zeit des Prinzen Eugen. Einfluß und Bedeutung der Kaiserinnen Eleonora Magdalena Theresia, Amalie Wilhelmine und Elisabeth Christine, in: Karl GuTKAS (Hg.), Prinz Eugen und das barocke Österreich (Salzburg 1985) 65-72.

Wolfgang MARTENS, Die Botschaft der Tugend. Die Aufklärung im Spiegel der deutschen Moralischen Wochenschriften (Stuttgart 1971).

Merkwürdige Stellen aus dem politischen Testamente Josephs II, in: Schleswigsches, ehem. Braunschweigisches Journal 1 (1792) 455-475.

Ernst MiLberG, Die deutschen moralischen Wochenschriften des 18. Jahrhunderts (Meissen 1880).

Friedrich Carl von Moser, Teutsches Hofrecht: in zwölf Büchern, Bd. 2 (Franckfurt-Leipzig 1755).
Friedrich Carl von MOSER (Hg.), Ungedrucktes und unterdrucktes merkwürdiges Testament Friderich Wilhelms des Großen Churfürstens zu Brandenburg vom 20. Merz 1688, in: Patriotisches Archiv 9 (1788) 137-244.

Friedrich Carl von MOSER (Hg.), Ungedruktes Testament Pfalzgrafen Wolfgangs Herzogs zu Neuburg, Zweibrücken etc. vom 18. August 1568. nebst der Confirmation Kayser Maximilians II. vom 7. Apr. 1570. Grund-Gesetz des Pfälzischen Hauses, in: Patriotisches Archiv 10 (1789) 3-156.

Johann Jacob MosER, Neues Teutsches Staats=Recht, Bd. 13: Von der Teutschen Reichs-Staende Landen, deren Landstaenden, Unterthanen, Landes-Freyheiten, Beschwerden, Schulden und Zusammenkuenfften nach denen Reichs-Gesetzen und dem Reichs-Herkommen, wie auch aus denen teutschen Staats-Rechts-Lehrern und eigener Erfahrung [...], 1, 3. Buch (Franckfurt-Leipzig 1769).

Johann Nicolaus MYLER AB EHRENBACH, Archologia ordinum imperialium, seu de principum \& aliorum statutuum imperum rom. germanico priscâ origine (Tübingen 1663).

Thomas PAINE, Rights of Man, in: The writings of Thomas Paine, Bd 2: 1779-1792, collected and edited by Moncure Daniel ConWAY, (Reprint of 1894 edition, London 1996) 258-400.

Veronika PокOMY, Clementia Austriaca. Studien zur besonderen Bedeutung der Clementia Principis für das Haus Habsburg. (phil. Diss., Univ. Wien 1973).

Johann Stephan PÜTTER, Versuch einer academischen Gelehrten-Geschichte von der Georg-AugustusUniversität zu Göttingen, Bd. 2 (Göttingen 1788).

Johann Stephan PÜTTER, Erörterungen und Beyspiele des Teutschen Staats- und Fürstenrechts, Bd. 1: Von der Anwendung Römischer Gesetze (Göttingen 1793).

Joseph Marie QUÉRARD, Les supercheries littéraires dévoilées, Bd. 2 (Paris 1847).

Fritz von REINÖHL, Das politische Vermächtnis Kaiser Franz' I., in: Historische Blätter 7 (1937) 71-78.

Susan RICHTER, Vor dem zeitlichen guet frundt im Himmel machen. Von der Erlangung des Seelenheils am Beispiel der frühneuzeitlichen Testamente der Herzöge von Bayern und Pfalz-Neuburg, in: Markwart Herzog, Cecilie HOLbBerg (Hgg.), Seelenheil und irdischer Besitz. Testamente als wirtschafts-, rechts- und sozialhistorische Quellen für den Umgang mit den, letzten Dingen' (Konstanz 2007) 53-65.

Susan RICHTER, Fürstentestamente der Frühen Neuzeit. Politische Programme und Medien intergenerationeller Kommunikation (= Schriftenreihe der 
Historischen Kommission bei der Bayerischen Akademie der Wissenschaften 80, Göttingen 2009).

Julius Bernhard von RoHR, Einleitung zur Ceremoniel-Wissenschafft der Grossen Herren (ND Weinheim 1990).

Alain RuIZ, Anno 1790 und 1792, als die Kaiser Joseph II. und Leopold II. starben. Stimmen deutscher Aufklärer im Spannungsfeld von Josephinismus und Jacobinismus, in: Wolfgang SCHMALE, Renate ZEDINGER, Jean MONDOT (Hgg.), Josephinismus - eine Bilanz/Échecs et réussites du Joséphisme (= Jahrbuch der Österreichischen Gesellschaft zur Erforschung des achtzehnten Jahrhunderts 22, Bochum 2008) 143-171.

Oskar SASHEGYI, Zensur und Gottesfreiheit unter Joseph II. Beitrag zur Kulturgeschichte der Habsburger Länder (Budapest 1958).

Hanno SCHMITT, Vernunft und Menschlichkeit. Studien zur philanthropischen Erziehungsbewegung (Bad Heilbrunn 2007).

Axel SchumanN, Berliner Presse und Französische Revolution. Das Spektrum der Meinungen unter preußischer Zensur (phil. Diss., TU Berlin 2001) [http://opus.kobv.de/tuberlin/volltexte/2001/318/p df/schumann_axel.pdf] abgerufen am 10.05. 2010).

Eberhard STRAUB, Drei letzte Kaiser. Der Untergang der großen europäischen Dynastien (Berlin 1988).

Ernst Wangermann, Die Waffen der Publizität. Zum Funktionswandel der politischen Literatur unter Joseph II. (Wien-München 2004).

Wolfgang E. J. WEBER, Dynastiesicherung und Staatsbildung. Die Entfaltung des frühmodernen Fürstenstaates, in: Wolfgang E. J. WeBER (Hg.), Der Fürst. Ideen und Wirklichkeiten in der europäischen Geschichte (Köln 1998) 91-136.

Michael WILDT, Generation als Anfang und Beschleunigung, in: Ulrike JUREIT (Hg.), Generationen. Zur Relevanz eines wissenschaftlichen Grundbegriffs (Hamburg 2005) 160-179.

Johann Heinrich ZEDLER (Hg.), Grosses vollständiges Universal-Lexicon aller Wissenschafften und Künste, Bd. 2 (Halle-Leipzig 1732). 